\title{
Polyglucosan body myopathy type 1
}

INSERM

\section{Source}

INSERM. (1999). Orphanet: an online rare disease and orphan drug data base.

Polyglucosan body myopathy type 1. ORPHA:397937

Polyglucosan body myopathy type 1 is a rare, genetic, glycogen storage disorder characterized by polyg lucosan accumulation in various tissues, manifesting with progressive proximal muscle weakness in the lower limbs and rapidly progressive, usually dilated, cardiomyopathy. Hepatic involvement and growth retardation may be associated. Early-onset immunodeficiency and autoinflammation, presenting with recurrent bacterial infections, have also been reported. 